Article

\title{
Optimal Sizing of Standalone Photovoltaic System Using Improved Performance Model and Optimization Algorithm
}

\author{
Tamer Khatib ${ }^{1, *(1)}$ and Dhiaa Halboot Muhsen ${ }^{2}$ (E) \\ 1 Department of Energy Engineering and Environment, An-Najah National University, Nablus 97300, Palestine \\ 2 Department of Computer Engineering, University of Mustansiriyah, Baghdad 10001, Iraq; \\ dhiaahm@uomustansiriyah.edu.iq \\ * Correspondence: t.khatib@najah.edu
}

Received: 10 February 2020; Accepted: 9 March 2020; Published: 13 March 2020

check for updates

\begin{abstract}
A standalone photovoltaic system mainly consists of photovoltaic panels and battery bank. The use of such systems is restricted mainly due to their high initial costs. This problem is alleviated by optimal sizing as it results in reliable and cost-effective systems. However, optimal sizing is a complex task. Artificial intelligence (AI) has been shown to be effective in PV system sizing. This paper presents an AI-based standalone PV system sizing method. Differential evolution multi-objective optimization is used to find the optimal balance between system's reliability and cost. Two objective functions are minimized, the loss of load probability and the life cycle cost. A numerical algorithm is used as a benchmark for the proposed method's speed and accuracy. Results indicate that the AI algorithm can be successfully used in standalone PV systems sizing. The proposed method was roughly 27 times faster than the numerical method. Due to AI algorithm's random nature, the proposed method resulted in the exact optimal solution in 6 out of 12 runs. Near-optimal solutions were found in the other six runs. Nevertheless, the nearly optimal solutions did not introduce major departure from optimal system performance, indicating that the results of the proposed method are practically optimal at worst.
\end{abstract}

Keywords: photovoltaic; standalone; sizing; optimization; DEMO

\section{Introduction}

Photovoltaic (PV) technology is one of most promising ways of harvesting the unlimited and free solar energy. However, PV technology performance depends on several environmental factors, such as the unpredictable solar radiation [1,2]. The inclusion of secondary energy sources (such as storage systems) improves the reliability of PV systems but also increases their cost. The high initial cost of PV systems is one of the main factors that hinder their use [3]. Therefore, PV systems should be optimized to achieve high reliability at the least possible expenses. System's sizing is a process in which PV system components are chosen such that an optimal balance between the system's availability and cost is obtained [4]. An optimally sized standalone PV system (SAPV) is considered as a promising application in locations where grid extension is uneconomical [5].

Previous SAPV sizing methods can be broadly classified into five categories; intuitive, numerical, analytical, artificial intelligence (AI), and hybrid methods. In intuitive methods [6-8], simple empirical equations are used to find the SAPV component sizes. These methods are heavily dependent on the designer's experience. The fluctuating nature of solar radiation is not considered, rather average values of solar radiation are used in these methods. Such methods offer the advantage of being simple, however they may lead to either oversized costly systems or undersized unreliable systems due to 
their inaccuracy. Also, the system availability cannot be quantified in these methods. Meanwhile, numerical methods [9-12] are simulation-based methods. In these methods, a predetermined range of PV/Battery numbers is linearly searched through. With such a method, reliability can be defined systematically. Numerical algorithms provide accurate results, provided that rigorous SAPV models and small time steps (hourly or less) are used. A requirement for good numerical sizing is long time series of meteorological data, however such data are not easily available. In addition, these methods require heavy computations and may take enough time to be deemed impractical [13]. A numerical algorithm's optimal result consists of one solution that is based on a predetermined availability level. This practice, as the authors of [1] have stated, does not offer the option of largely improving system availability at little extra costs. Numerical methods can be used to find all of the PV/Battery pairs that give a certain reliability level for a load. The plots of these pairs are called isoreliability lines (curves) [14].

In analytic methods [15-17], isoreliability lines are first obtained from a numerical method. Then, these curves are fit into mathematical equations. The derived equations describe SAPV components size as functions of reliability. These equations are simple, more accurate than intuitive equations, and they require commonly available weather data. However, their derivation is difficult. Also, this method's results are site-specific.

On the other hand, artificial intelligence (AI) techniques have been utilized in SAPV sizing. Contributions can be classified into two main groups; artificial neural network-based (ANN) methods and metaheuristic methods. Khatib and Elmenreich [18] developed a generalized regression neural network (GRNN) SAPV sizing method for Malaysia. The inputs for the GRNN are latitude, longitude, and the loss of load probability (LLP), while the outputs are the sizing ratios. The GRNN gave more accurate results than an analytical method. The difficulty of deriving analytical equations was eliminated but the results were still site-specific.

Instead of linearly searching every PV/Battery combination, metaheuristic AI algorithms randomly search for optimal solutions. Thus, they can be faster than numerical methods and can result in acceptably accurate results. Maleki et al. [19] presented a novel method for finding the optimal location and size of an SAPV in Iran. First, a geographical information (GIS)-based spatial model was developed to find the optimal site of the PV system. The spatial model was used to choose the optimal location according to 10 technical, environmental, and socio-economic criteria. Then, artificial bee colony (ABC) was used to find the optimal size of the SAPV. The proposed method is a single-objective with the total life cycle cost being the objective function to be minimized. One limitation of the sizing method is that it has to be run separately for each desired reliability level. Also, the authors have not validated the accuracy of the sizing method's result nor have they reported the execution time for the sizing method.

ABC was also applied in an SAPV sizing method in Egypt [20]. Two objective functions were developed, the first one is the PV module's power and the other is the life cycle cost (LCC). The goal was to maximize the first objective function and to minimize the second one subject to the constraints; tilt angle, azimuth angle, and the number of days. The authors concluded that their method is more optimal than a previous GA-based method. However, the authors did not report how efficient the algorithm was execution time-wise.

Another recent attempt of using AI in SAPV sizing was made by [21]. In this study, the authors aimed at finding not only the optimal numbers of each system components, but also the optimal component models from about 130,000 possible combinations. First, a numerical algorithm was run to be used as a benchmark for accuracy and execution time. Then, a Firefly-based sizing algorithm was executed. Experiments showed that the proposed algorithm matched the numerical algorithm accuracy but with a substantially less operation time. The method was proven to be superior to other AI-based methods; particle swarm optimization (PSO), evolutionary programming (EP), and GA [21]. A major limitation of this sizing method is that it is a single objective method that does not consider any cost calculations. Intuitively, there is a large number of components sets that meets the desired 
reliability level, however without cost comparison, we do not know which of those sets is the most economical. Therefore, the optimal results are questionable.

Single-objective optimization has also been applied to hybrid systems. In [22], an off-grid PV/biomass hybrid system was sized to supply a load in a remote area in Iran. In this study, the objective function was the total net present cost (TNPC) subject to the constraints: The PV panels' area, the size of the biomass generator, and the loss of power supply probability (LSPS). As for the searching algorithm, harmony search (HS) algorithm was used.

Another single-objective hybrid system sizing study can be found in [23]. Here, the authors proposed a novel PV/Wind/Battery sizing framework that combined three metaheuristic algorithms, chaotic search (CS), simulated annealing (SA), and HS into a unified algorithm. The objective function in this study was the total annual cost of the system. Also, three constraints were proposed; these are the numbers of the PV panels, wind turbines, and batteries. It was noted that the unified algorithm, while being simple, performed more efficiently than other tested approaches.

Other AI-based SAPV sizing methods include multi-objective optimization. In [20], two objective functions were developed to optimally size an SAPV in Egypt. The first one is the PV module's power and the other is the life cycle cost (LCC). The goal was to maximize the first objective function and to minimize the second one subject to the constraints; tilt angle, azimuth angle, and the number of days. The authors concluded that their method is more optimal than a previous GA-based method. However, the authors did not report how efficient the algorithm was execution time-wise.

On the other hand, AI-based optimization methods were utilized for hybrid renewable systems sizing as well such as PSO, crow searching algorithm [24-26]. In these researches, a similar methodology was followed whereas three main objective functions were adapted, which are LSPS, TNPC, and the $\mathrm{CO} 2$ emission.

A recent review highlights the need for new, fast, and accurate sizing methods [27]. Other recent reviews [28-30] demonstrate the increased attention given to AI techniques' use in sizing as they have been proven to be more successful than conventional optimization methods. These reviews stated that the most two important issues to be considered when optimizing a SPAV are system models and the efficiency and speed of the utilized AI algorithm. These issues do really affect the accuracy of the obtained results. Therefore, the contribution of the present research work can be described by representing the SAPV system sizing problem as a multi-objective optimization problem, which was solved by a novel differential evolution multi-objective optimization (DEMO) algorithm [31]. Moreover, improved PV array models are utilized in this research. The multi-objectives are simultaneously minimized, which is rarely done in the literature, to obtain a Pareto-optimal set of configurations. The proposed system in this research is for a household in Baghdad, Iraq. Measured hourly solar radiation and temperature data for one year are used along with an hourly load profile. Finally the proposed method's accuracy and execution time are compared to those of the numerical method.

\section{Modeling of Standalone PV System}

\subsection{Modeling of Photovoltaic Array}

In this research, the utilized SAPV model consists of two main parts, a PV cell model and a battery model. The single-diode $R_{p}$ model [30] is used in this study. The I-V characteristics of the PV cell are obtained by

$$
I=I_{P h}-I_{o}\left[\exp \left(\frac{q\left(V+R_{s} I\right)}{a K T}\right)-1\right]-\frac{V+I R_{S}}{R_{p}}
$$

where $I$ and $V$ are the cell's output current in $(\mathrm{A})$ and voltage in $(\mathrm{V})$, respectively. $I_{P h}$ is the photo current in (A), $I_{O}$ is the diode saturation current in (A), $R_{S}$ and $R_{P}$ are the cell's series and parallel resistance values in (Ohms), respectively, $a$ is the diode's ideality factor, $K$ is Boltzmann's constant $\left(1.3806503 \times 10^{-23} \mathrm{~J} / \mathrm{K}\right)$, and $T$ is the cell temperature in $(\mathrm{K})$. 
The five parameters of this model $\left(I_{P h}, I_{S}, a, R_{S}\right.$, and $\left.R_{P}\right)$ depend on temperature and radiation [30,31]. In this study, differential evolution with adaptive mutation (DEAM) is proposed for estimating the five parameters by using the method in [32]. In DEAM, a set of measured I-V curves is first obtained [32]. This set is shown in Figure 1 for the used PV module (Kyocera KC120-1). Then, for each measured I-V curve, DEAM is used to find the values of the five parameters that result in the least erroneous simulated I-V curves.

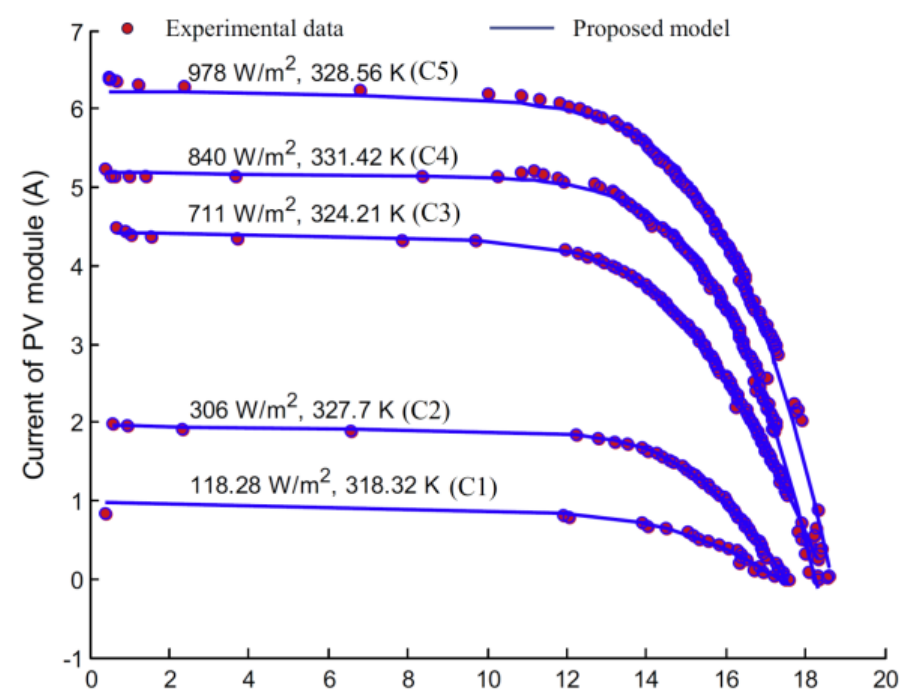

Figure 1. Experimental and simulated I-V curves of photovoltaic (PV) modules using DEAM [32].

This is done by formulating an objective (fitness) function that calculates the root mean square error between measured and simulated PV module's current. The objective function is described by,

$$
f(\theta)=\sqrt{\frac{1}{n} \sum_{i=1}^{n} P\left(V_{e}, I_{e}, \theta\right)^{2}}
$$

where

$$
P\left(V_{e}, I_{e}, \theta\right)=I_{e}-I
$$

where $V_{e}$ and $I_{e}$ are the experimental (measured) values of the PV panel's voltage and current, respectively, $\theta$ is a vector whose elements are the five parameters and $n$ is the number of PV module's current measurements of one I-V curve. DEAM is based on the classical differential evolution (DE) algorithm [33], and it consists of the same steps (initialization, crossover, and selection). As for mutation, the process in DEAM algorithm is different. In the DEAM algorithm, two mutation types may be used depending the type of the objective function. These types are conventional mutation in differential evolution algorithm $\left(M_{d}\right)$, and the mutation of electromagnetism algorithm's $\left(M_{e}\right)$. This process assures better accuracy and lower execution time [33].

The flow chart of DEAM is shown in Figure 2. Similar to the DE algorithm, the solution is called individual, while the group of solutions are called population. Parent is the first population that a generation starts, while child is the fourth resulting pollution in a specific generation. 


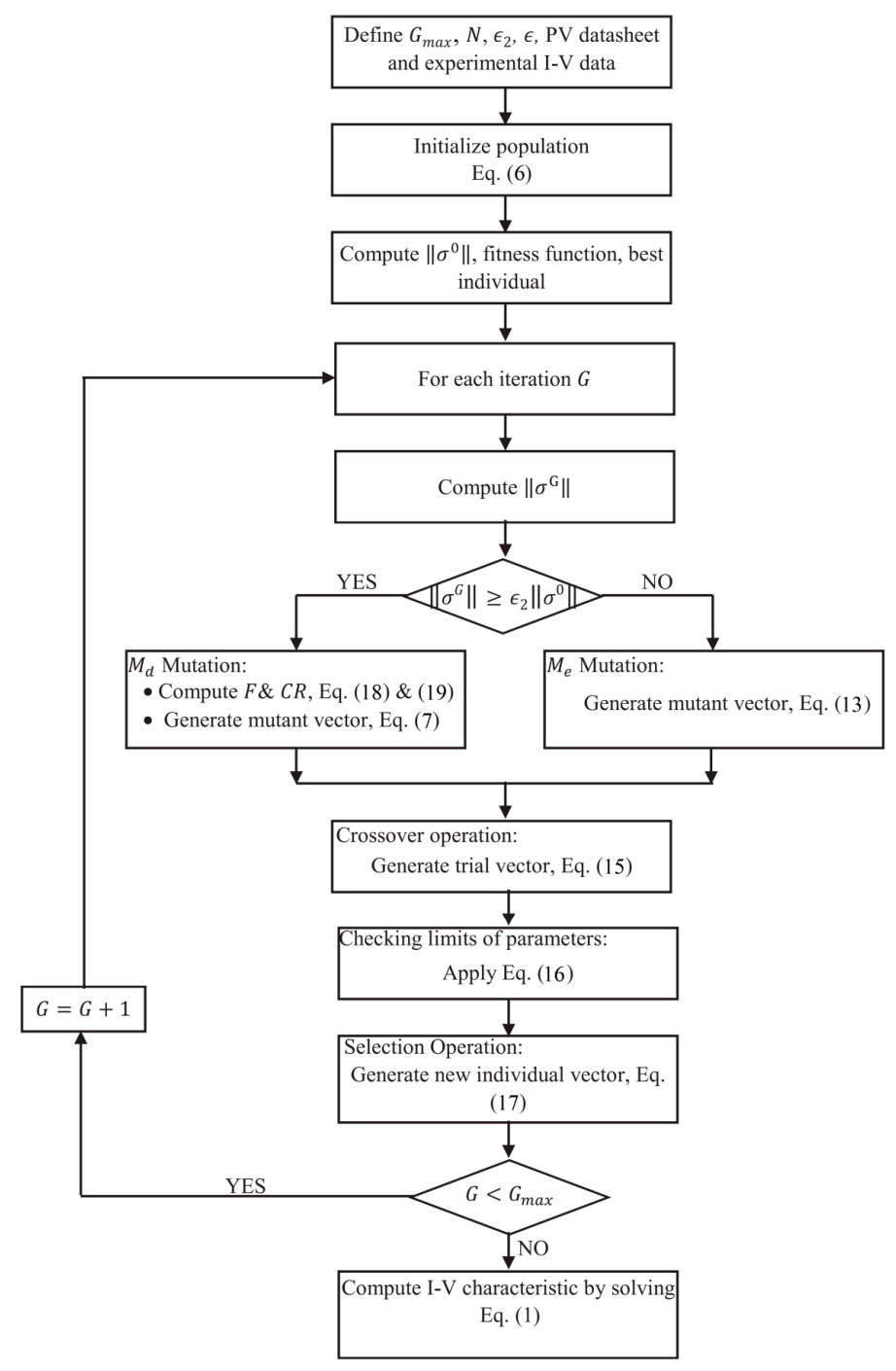

Figure 2. Differential evolution with adaptive mutation (DEAM)'s flow chart [32].

In general, the variables of any optimization algorithm that are controlled to reach the optimal solution are called decision variables. Thus, in this research, the five parameters of the PV modules are the decision variables. During the optimization process, the solution space matrix has a specific number of decision variables (rows of a population). Meanwhile, this matrix has a specific number of number of individuals (columns of a population). The following equation describes a population $(P O P)$ of a generation $(G)$,

$$
P O P^{G}=\left[X_{1}^{G}, X_{2}^{G}, \ldots X_{N}^{G}\right]=\left[X_{i}^{G}\right]
$$

where

$$
X_{i}=\left[X_{1, i}, X_{2, i}, \ldots, X_{D, i}\right]=\left[X_{d, i}\right]
$$

where $X_{i}^{G}$ is an individual vector that implies decision variables (target vector) in the generation $G, d$ is the number of decision variables (from 1 to $D$ ), and $X_{d, i}$ is the value of the $d$ th decision variable in the $i$ th individual. Finally, $i$ denotes the index of individuals (from 1 to $N$ ). The details of the proposed algorithm's steps are presented next.

- Initialization 
A population is created randomly whereas the value of each decision variable in each individual is determined as follows,

$$
X_{d, i}^{0}=X_{d, L, i}^{0}+R\left(X_{d, H, i}^{0}-X_{d, L, i}^{0}\right)
$$

where $X_{d, i}^{0}$ is the initial value of the $d$ th decision variable in the $i$ th individual, $X_{d, L, i}$ and $X_{d, H, i}$ are the lowest and highest limits for a decision variable's value, and $R$ is a random number that lies between zero and one. This equation guarantees uniformly distributing the initial values of the five parameters.

\section{- Mutation}

After a $D$ by $N$ sized initial population is formed, the mutation process is executed either according G

to $M_{d}$ or $M_{e}$ based on a condition. In $M_{d}$, a mutant vector $X_{i}$ is generated for each target vector $X_{i}^{G}$ according to the equation below,

$$
\hat{X}_{i}^{G}=X_{\alpha}^{G}+F\left(X_{\beta}^{G}-X_{\gamma}^{G}\right)
$$

$\alpha, \beta$, and $\gamma$ are different individual indices and there are randomly selected subjects to not having any of these indices coinciding with the target vector's index; $F$ is a scaling the mutation process parameter and it value is usually in the range of $(0.5,1)$.

As for $M_{e}$ the mutation process is also based on three distinct individuals that are chosen randomly from the current population. However, here one of the selected individuals can be the same as the target individual. Mutation in the EM algorithm depends on the force applied by two of the three individuals $\left(X_{\beta}^{G}\right.$ and $X_{\gamma}^{G}$ ) to the third one $\left(X_{\alpha}^{G}\right)$. In order to get this force, the charges $q_{\alpha \beta}^{G}$ (between $X_{\alpha}^{G}$ and $X_{\beta}^{G}$ ) and $q_{\alpha \gamma}^{G}$ (between $X_{\alpha}^{G}$ and $X_{\gamma}^{G}$ ) are first calculated,

$$
\begin{gathered}
q_{\alpha \beta}^{G}=\frac{f\left(X_{\alpha}^{G}\right)-f\left(X_{\beta}^{G}\right)}{f\left(X_{w}^{G}\right)-f\left(X_{b}^{G}\right)} \\
q_{\alpha \gamma}^{G}=\frac{f\left(X_{\alpha}^{G}\right)-f\left(X_{\gamma}^{G}\right)}{f\left(X_{w}^{G}\right)-f\left(X_{b}^{G}\right)}
\end{gathered}
$$

where $f(X)$ is the fitness value for the individual $X, X_{w}^{G}$ and $X_{b}^{G}$ are the worst and best individuals in the population $G$, respectively. The force that $X_{\beta}^{G}$ and $X_{\gamma}^{G}$ exert on $X_{\alpha}^{G}$ is given by,

$$
F_{\alpha}^{G}=F_{\alpha \beta}^{G}+F_{\alpha \gamma}^{G}
$$

where

$$
\begin{aligned}
& F_{\alpha \beta}^{G}=\left(X_{\beta}^{G}-X_{\alpha}^{G}\right) q_{\alpha \beta}^{G} \\
& F_{\alpha \gamma}^{G}=\left(X_{\gamma}^{G}-X_{\alpha}^{G}\right) q_{\alpha \gamma}^{G}
\end{aligned}
$$

Finally, the mutant vector according to $M_{e}$ can be found by,

$$
\hat{X}_{i}^{G}=X_{\alpha}^{G}+F_{\alpha}^{G}
$$

The criterion by which DEAM chooses between $M_{d}$ or $M_{e}$ is given below,

$$
\text { Mutation operation }=\left\{\begin{array}{l}
M_{e} \text { if }\left\|\sigma^{G}\right\|<\varepsilon_{2}\left\|\sigma^{0}\right\| \\
M_{d} \text { otherwise }
\end{array}\right.
$$


where $\sigma^{G}$ is the standard deviation vector of a population's row vectors for the $G$ th generation, $\sigma^{0}$ is the same as $\sigma^{G}$ but for the initial generation, $\|\sigma\|$ is the norm of that vector, and $\varepsilon_{2}$ is a parameter that controls switching between $M_{e}$ and $M_{d}$; this parameter is given a value within the interval [0,1].

\section{- Crossover}

Here, the conventional crossover process of DE algorithm's is applied. The result of this phase $i$ an initial vector called $y_{d, i}^{G}$. This vector is tested then according to the following equation,

$$
y_{d, i}^{G}=\left\{\begin{array}{l}
\hat{X}_{d, i}^{G} \text { if } R \leq C R \text { or } d=d_{R} \\
X_{d, i}^{G} \text { otherwise }
\end{array}\right.
$$

where $d_{R}$ is an index with a value in the range of $(1, \mathrm{D}), C R$ is the cross over rate that controls the operation of the crossover, and it usually has a value in range of $(0.5,1)$.

Using the role implied in equation $15, y_{d, i}^{G}$ is named target vector $X_{d, i}^{G}$ or mutant vector $X_{d, i}$. Here, if $C R$ has a value of one, the mutant vector is chosen as the trial vector. However, a trial vector may contain decision variable values that lie outside the preset limits for the adapted variables. Thus, the reassigning process of the trial vector by using Equation (16) in the case that the trial vector violate limits assigned for the variables.

$$
y_{d, i}^{G}=X_{d, L, i}^{G}+R\left(X_{d, L, i}^{G}-X_{d, L, i}^{G}\right)
$$

\section{- Selection}

Again, selection here is performed according to the conventional DE algorithm. The selection stage begins when all individuals of the current population have been recombined (have gone through mutation and crossover). In the selection stage, the best individuals from the trial and target populations are chosen. Since the objective function is defined in terms of RMSE, the individuals with the smallest fitness values are selected as the individuals of the parent population for the next generation. This process is described by,

$$
X_{i}^{G+1}=\left\{\begin{array}{l}
y_{i}^{G} \text { if } f\left(y_{i}^{G}\right)<f\left(X_{i}^{G}\right) \\
X_{i}^{G} \text { otherwise }
\end{array}\right.
$$

The four steps are repeated for the new generation, and the ones that follow, until the maximum number of generations $\left(G_{\max }\right)$ is reached.

The performance of $\mathrm{DE}$ is dependent on the mutation factor $(F)$ as well as the crossover rate $(C R)$. These parameters normally have constant values in the classical DE algorithm. Improper values of these parameters can result in a long convergence time. In the proposed algorithm, the values of both $F$ and $C R$ are governed by the following logistic sigmoid function,

$$
\begin{gathered}
F, C R=L\left(\frac{1}{1+\exp (-K W)}+H\right) \\
w=R\left[f\left(X_{\text {best }}^{G}\right)-f\left(X_{\text {best }}^{G-1}\right)\right]
\end{gathered}
$$

where $L$ and $H$ are two constants that guarantee having normal $F$ and $C R$ values (between 0.5 and 1 ), $L=0.5$ and $H=1, K$ is a factor that determines the steepness of the logistic sigmoid function's curve, and $X_{\text {best }}^{G}$ and $X_{\text {best }}^{G-1}$ the are the best individuals for the generations $G$ and $G-1$, respectively. 
The absolute error (AE) is used to measure the error between the current simulated using the estimated parameters $\left(I_{S}\right)$ and the experimental current $\left(I_{e}\right)$. The average error is calculated as follows,

$$
\mathrm{AE}=\left|I_{S}-I_{e}\right|
$$

To get the module-level current and voltage, the PV cell current and voltage are modified as follows,

$$
\begin{gathered}
I_{M}=N_{P C} I \\
V_{M}=N_{S C} V
\end{gathered}
$$

where $N_{P C}$ and $N_{S C}$ are the number of parallel and series cells in a module respectively, $I_{M}$ is the module's current, and $V_{M}$ is the module's voltage. Similarly, the array level current and voltage are determined as follows,

$$
\begin{aligned}
I_{A} & =N_{P M} I_{M} \\
V_{A} & =N_{S M} V_{M}
\end{aligned}
$$

where $I_{A}$ and $V_{A}$ are the array's current (A) and voltage $(\mathrm{V}), N_{P M}$ is the number of parallel modules, and $N_{S M}$ is the number of series models. The output of the PV array in (W) is simply,

$$
P_{P V}=I_{A} V_{A}
$$

An MPPT controller is assumed to be used in this method. Therefore, the output power is always maximum. Since an hourly time step is used, $P_{P V}$ is also the energy produced per hour from the PV panels.

\subsection{Battery Model}

The lead acid battery model developed in [34] will be used in this paper. This model has been shown to be adequate for simulating SAPVs. It is an electrical equivalent circuit-based model that has two elements, a voltage source $\left(V_{1}\right)$ and a series resistor $\left(R_{1}\right)$ as shown in Figure 3.

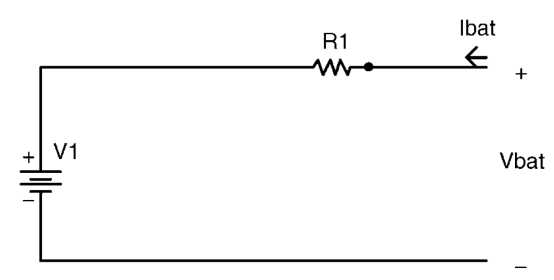

Figure 3. The electrical equivalent circuit of the battery model [29].

It consists of two modes, the charge mode and the discharge mode. The equations for the charge mode are,

$$
\begin{gathered}
V_{1}=V_{C H}=(2+0.148 B) n s \\
R_{1}=R_{C H}=\frac{0.758+\frac{0.1309}{1.06-B}}{\text { SOCmax }} n s \\
B=S O C / \text { SOCmax } \\
V_{b a t}=V_{C H}+I_{b a t} R_{C H} \\
\text { SOCmin }=(1-D O D) C_{b a t}
\end{gathered}
$$

where $V_{C H}$ is the charge mode source voltage, $n s$ is the number of battery cells in series, SOCmax is the maximum value of the battery charge in (Wh), SOC is the instantaneous value of the battery charge in $(\mathrm{Wh})$, and $V_{b a t}$ and $I_{b a t}$ are the battery cell's voltage $(\mathrm{V})$ and current $(\mathrm{A})$, respectively. SOCmin is 
the minimum allowed state of charge in (Wh). DOD is the maximum allowed depth of discharge percentage. Specifying this value is important as it has a great impact on the battery's life. Greater values of $D O D$ lead to shorter battery life spans. $C_{b a t}$ is the battery's nominal capacity in (Wh).

The equations for the discharge mode are given below,

$$
\begin{gathered}
V_{1}=V_{D C H}=(1.962+0.124 B) n s \\
R_{1}=R_{D C H}=\frac{0.19+\frac{0.1037}{B-0.14}}{S O C \max } n s \\
V_{b a t}=V_{D C H}+I_{b a t} R_{D C H}
\end{gathered}
$$

$I_{b a t}$ is positive in the charge mode and is negative in the discharge mode. The equation that updates the battery's state of charge is given as,

$$
\operatorname{SOCn}(t)=\operatorname{SOCn}(t-1)+\frac{1}{\operatorname{SOC} \max } \int\left(k V_{1} I_{\text {bat }}\right)-(D \operatorname{SOC} n(t-1) \operatorname{Socmax}) d t
$$

where $\operatorname{SOC} n(t)$ is the instantaneous normalized (divided by SOCmax) state of charge at simulation step $t, \operatorname{SOC} n(t-1)$ is $\operatorname{SOC} n(t)$ of the previous time step, $k$ is the charge/discharge efficiency, and $D$ is the self-discharge rate in $\left(\mathrm{hr}^{-1}\right)$. Finally, the hourly energy that enters or leaves the battery is given by,

$$
E_{b a t}=I_{b a t} V_{b a t}
$$

\subsection{SAPV Energy Flow Model}

This model simulates the energy flow between the system components and the load. It links components' models together and simulates the operation of the entire system. The model's flowchart is shown in Figure 4. The simulation starts from $t$ values equals to 1 with an assumption that the battery is fully charged as purchased.

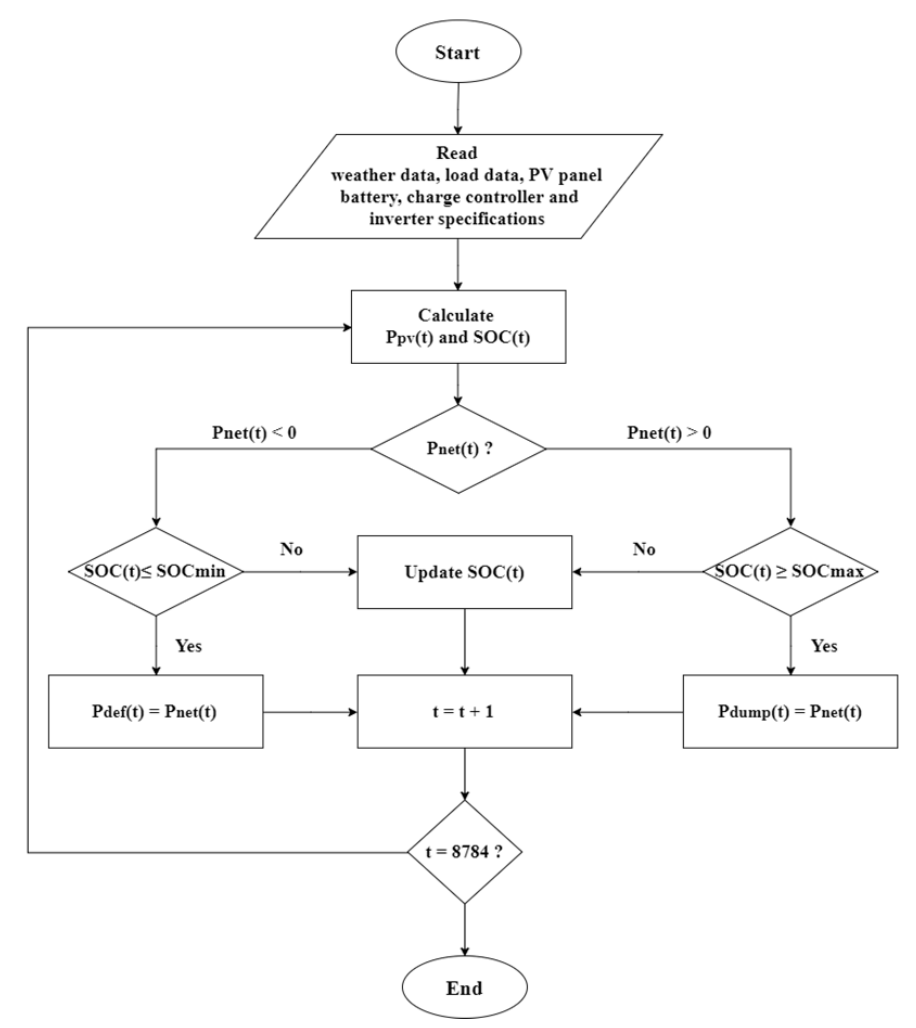

Figure 4. The flow chart of standalone PV (SAPV) energy flow model. 
In this study, a simulation duration of one year is used. The time step for this duration is one hour. In each hour, the power balance equation is solved,

$$
P_{N E T}=P_{P V}-P_{L O A D} / \eta_{I N V}
$$

where $P_{P V}$ is the power produced by the PV array. $P_{L O A D}$ is the load power, $\eta_{I N V}$ is the inverter's efficiency, and $P_{N E T}$ is net power.

Now, $P_{N E T}$ can be positive, negative, or equal to zero. If $P_{N E T}$ is positive, it means the PV modules are generating more power than is required by load. The extra power $\left(P_{N E T}\right)$ is used to charge the battery if its SOC is lower than SOCmax and SOC increases. Otherwise, this extra power is fed to a dump load and $S O C$ is fixed at its maximum limit. This is when $P_{N E T}$ is stored as dump (excess) power $\left(P_{\text {DUMP }}\right)$.

When $P_{N E T}$ is negative, it means the PV array is producing less power than the load requires. Again, two possibilities exist. Either the extra power requirement (that the PV array cannot meet) is taken from the battery bank. This happens when its SOC is above the minimum allowed level (SOCmin), the battery's SOC decreases in this case. Or, the SAPV fails to meet the load if the battery $S O C$ is below SOCmin. $P_{N E T}$ is stored as deficit power $\left(P_{D E F}\right)$ in this case and SOC is fixed at its minimum bound. Finally, when $P_{N E T}$ is zero, the load is completely met by the PV array and the battery $S O C$ remains unchanged (except for the small self-discharge).

\subsection{Technical and Economical Parameters}

Before we can apply sizing algorithms to the SAPV model, we need to define technical and economical parameters so as to systematically define the reliability and the cost of the SAPV. In this study, loss of load probability (LLP) is used to measure the reliability of the system. As for cost of the SAPV, it is quantified by the life cycle cost (LCC) parameter. The two parameters are explained next.

\subsubsection{Loss of Load Probability}

It is defined as the ratio of the total deficit energy to the total load demand over a period of time [35]. Usually, this period of time is long enough to get a good representation of reliability. LLP is given by [12],

$$
\text { LLP }=\frac{\sum_{1}^{8784} \text { Deficit Energy }}{\sum_{1}^{8784} \text { Load Energy }}
$$

An LLP of one means that the system does not supply any load energy, while an LLP of zero indicates that there are no power shortages at all. The chosen LLP for this study is 0.01 . That is, we aim to find the cheapest PV/Battery pair that gives an LLP of 0.01 .

\subsubsection{Life Cycle Cost}

Life cycle cost (LCC) is the sum of the costs of system's components during its life cycle considering the present worth (PW) value [36]. By using the method described in [35] for the calculation of LCC, the LCC function of a standalone PV system consists of four main parts, which are the initial cost $\left(C_{C A P}\right)$, the maintenance $\operatorname{cost}\left(C_{M}\right)$, the replacement $\operatorname{cost}\left(C_{R}\right)$, and the salvage value $\left(C_{S}\right) . C_{C A P}$ is simply the cost of system's components such as PV modules, battery cells, charge controller, installation cost, etc. Meanwhile, maintenance $\operatorname{cost}\left(C_{M}\right)$ is usually considered as a constant annual payment and it can be calculated using the equations below,

$$
\begin{aligned}
C_{M} & =C_{M O} P_{A} \\
P_{A} & =\frac{1-X^{n}}{1-X} \\
X & =\frac{1+i}{1+d}
\end{aligned}
$$


where $C_{M O}$ is the PW of the yearly maintenance cost, and $n$ is the SAPV lifetime in (years).

Replacement $\operatorname{cost}\left(C_{R}\right)$ is also a recurring payment, but it is not necessarily paid on a yearly basis. For instance, a battery bank may need to be replaced every five years. Again, the price of the component is liable to change in the future. The PW of purchasing new sets of the component to be replaced is $C_{R}$. Replacement cost is calculated as follows,

$$
C_{R}=C_{R O}\left(X^{n 1}+X^{n 2}+\ldots X^{n f}\right)
$$

where $C_{R O}$ is the present worth (PW) of the capital cost, while $n 1$ indicates is the year of first replacement process,

As for the salvage value, its value is assumed to be $0.14 \%$ of total PW value of the system [12]. Following that, LCC can be given as below,

$$
\mathrm{LCC}=C_{C A P}+C_{M}+C_{R}-C_{S}
$$

With the evaluation parameters defined, we can now apply sizing algorithms. In the next sections, the numerical and the proposed sizing algorithms will be explained.

\section{Optimal Sizing of SAPV}

The Numerical Algorithm

In general, a numerical algorithm method is usually used to optimize SAPV [12]. In this research, the numerical algorithm method is used as a benchmark for comparison purposes. Details about the numerical algorithm can be obtained from [12]. In this research, SAPV size is optimized by minimizing two objective functions, which are LLP and LCC. The steps of optimization are listed below in detail.

Step 1: The meteorological profile (solar radiation and temperature data) along with the load profile, technical components, and economic specifications are inserted.

Step 2: Determine the number of series PV modules and series batteries.

These are calculated so as to satisfy the system's DC voltage $\left(V_{D C}\right)$ requirement as follows,

$$
\begin{gathered}
N_{P S}=V_{D C} / V_{M P} \\
N_{B S}=V_{D C} / V_{B}
\end{gathered}
$$

where $V_{M P}$ is the module's nominal (maximum power point) voltage, $N_{B S}$ is the number of batteries in series, and $V_{B}$ is the battery's nominal voltage.

Step 3: Define decision variables limits.

In this method, two decision variables are used. These are the total number of PV panels $\left(N_{P V}\right)$ and the capacity of the battery bank $C_{B}(\mathrm{Wh})$. For comparison purposes, the same ranges for PV/Battery that were used in the numerical algorithms are utilized in the DEMO-based sizing method. Intuitive equations are used to determine limits for decision variables as follows [12],

$$
P=\frac{E_{L}}{\eta_{P V} \eta_{W} \eta_{I N V} A_{P V} P S H} S_{f}
$$

where $P$ is an estimate value for the total number of $P V$ modules, $E_{L}$ is the daily average load energy, $\eta_{P V}$ is the PV module's efficiency, $\eta_{I N V}$ and $\eta_{W}$ are efficiencies for the inverter and the wires respectively, $A_{P V}$ is the module's area in $\left(\mathrm{m}^{2}\right), \mathrm{PSH}$ (peak sun hours) is the number of hours per day during that a solar radiation of $1000 \mathrm{~W} / \mathrm{m}^{2}$ is available, and $S_{f}$ is a safety factor specified by the designer.

$$
C_{W H}=\frac{E_{L} D_{\text {auto }}}{D O D \eta_{B}}
$$


where $C_{W H}$ is an estimate value of the battery bank capacity $(\mathrm{Wh}), D_{\text {auto }}$ is the number of days the load is fed solely by batteries (days of autonomy), and $\eta_{B}$ is the battery efficiency. Now, the ranges for decision variables can be defined as follows,

$$
\begin{gathered}
P / 3 \leq N_{P V} \leq 5 P \\
C_{W H} / 3 \leq C_{B} \leq 5 C_{W H}
\end{gathered}
$$

Step 4: Run DEMO. Now, the AI algorithm goes through the steps mentioned earlier.

An individual is represented by a column vector containing two rows, $N_{P V}$ and $C_{B}$. A demonstrative example of how DEMO is applied to SAPV sizing is explained next. An initial set of solutions is randomly selected first $\left(\mathrm{A}_{\mathrm{INI}}, \mathrm{B}_{\mathrm{INI}}\right.$, and $\left.\mathrm{C}_{\mathrm{INI}}\right)$. Each solution is represented by its LLP/LCC pair. The initial solutions are replaced by better ones in each generation according to the Pareto improvement conditions. Given two solutions A and B, if A has a lower LLP (LCC) value than that of B with A's LCC (LLP) value at least equal to that of B, then A dominates B. After a number of such processes, the result is a set of Pareto-optimal solutions $\left(\mathrm{A}_{\mathrm{OPT}}, \mathrm{B}_{\mathrm{OPT}}\right.$, and $\left.\mathrm{C}_{\mathrm{OPT}}\right)$. The optimal solutions are non-dominant to each other. That is, LLP (LCC) of AOPT cannot be improved without causing LCC (LLP) of the same solution to deteriorate. The same applies to $\mathrm{B}_{\mathrm{OPT}}$ and $\mathrm{C}_{\mathrm{OPT}}$. At the extremes of the Pareto front, solutions with opposite qualities of fitness functions exist. Solution $\mathrm{S}_{\mathrm{TOP}}$ has the worst (or maximum) value of LLC and the best (or minimum) value of LLP. The opposite is true for solution $\mathrm{S}_{\mathrm{BOT}}$.

Step 5: If the algorithm reached the maximum number of generations, find the optimal configuration of the system. Here, the number PV $\left(N_{P M}\right)$ and batteries $\left(N_{P B}\right)$ that are connected in parallel, is given by,

$$
\begin{gathered}
N_{P M}=N_{P V, O P T} / N_{S M} \\
N_{P B}=C_{B, O P T} / C_{b a t}
\end{gathered}
$$

where $N_{P V, O P T}$ and $C_{B, O P T}$ are the optimal values found by the proposed optimization algorithm.

\section{Results and Discussion}

In this research, PV array model is developed and implemented first. The absolute percentage error between the measured and the simulated PV module's currents and under-five weather conditions (five different solar radiation and ambient temperature values) is provided in Table 1.

Table 1. DEAM's accuracy for PV array modeling as compared to three other methods.

\begin{tabular}{ccccc}
\hline Condition. & DEAM & Ishaque et al. [36] & Jiang et al. [37] & Khatib et al. [38] \\
\hline C1 & 0.0336 & 0.0387 & 0.0389 & 0.0478 \\
C2 & 0.0174 & 0.0261 & 0.0238 & 0.0978 \\
C3 & 0.0201 & 0.0268 & 0.0265 & 0.1320 \\
C4 & 0.0646 & 0.0844 & 0.0844 & 0.1001 \\
C5 & 0.1050 & 0.1104 & 0.1104 & 0.5661 \\
\hline
\end{tabular}

After that, hourly meteorological data for the year of 2016 were obtained from a meteorological station in the building of the Iraqi ministry of science and technology in Baghdad (at a latitude of $33.31^{\circ} \mathrm{N}$ and a longitude of $44.36^{\circ} \mathrm{E}$ ). The hourly solar radiation and temperature profiles are shown in Figure 5. The highest radiation value measured was $992 \mathrm{~W} / \mathrm{m}^{2}$, which occurred at the noon of June 11th. June had the highest monthly average solar radiation, which was about $313.4 \mathrm{~W} / \mathrm{m}^{2}$; while the lowest monthly average solar radiation was about $85.47 \mathrm{~W} / \mathrm{m}^{2}$ and was measured in December. The highest temperature (about $48^{\circ} \mathrm{C}$ ) and the lowest temperature (about $0.5^{\circ} \mathrm{C}$ ) were recorded in June and January, respectively. 

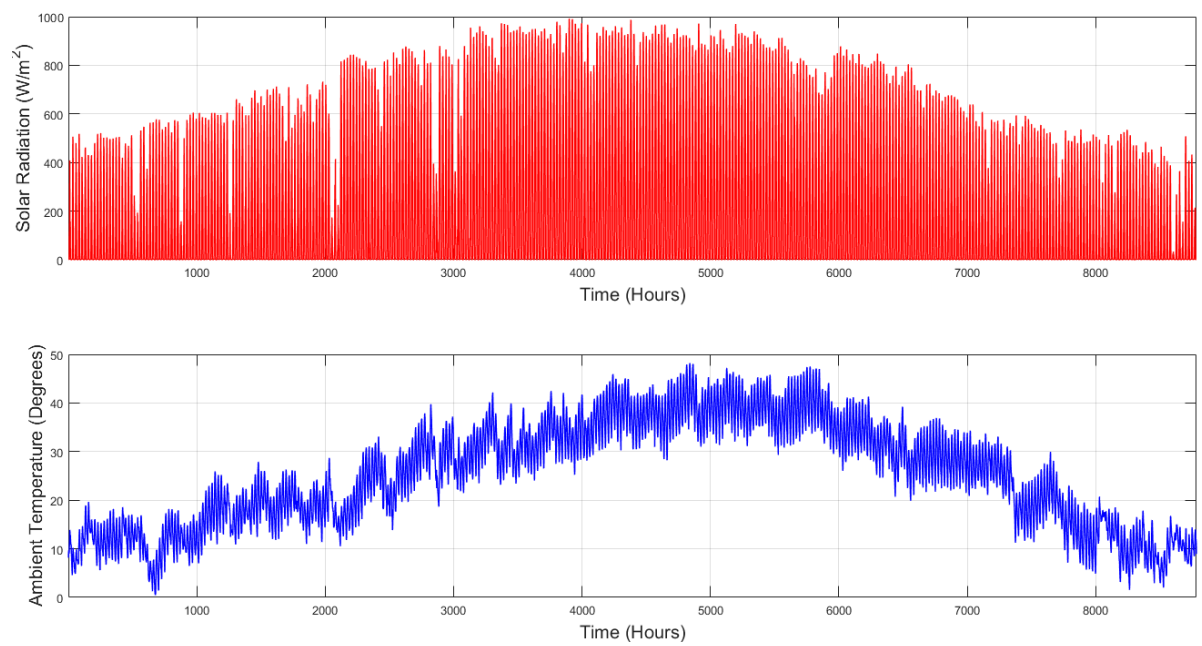

Figure 5. Hourly solar radiation and temperature profiles for Baghdad for the year of 2016.

A hypothetical hourly power load (Figure 6) was used. Although any other load profile can be used, the load cycle is assumed to repeat every day. The SAPV technical and economic specifications are given in Tables 2 and 3, respectively.

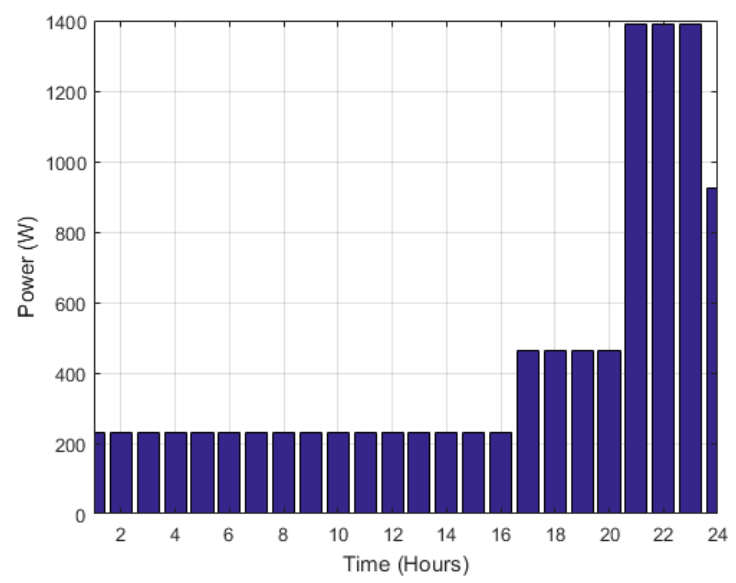

Figure 6. Daily load power profile.

Table 2. The technical specifications for the SAPV components used in this study.

\begin{tabular}{ccc}
\hline Component & Specification & Value \\
\hline PV Panel (KC120-1) & Maximum power at STC $\left(P_{M P}\right)$ & $120 \mathrm{Wp}($ Watts Peak $)$ \\
& Voltage at maximum power point $\left(V_{M P}\right)$ & $16.9 \mathrm{~V}$ \\
& Current at maximum power point $\left(I_{M P}\right)$ & $7.1 \mathrm{~A}$ \\
& Efficiency at STC $\left(\eta_{P V}\right)$ & $12.9 \%$ \\
Battery (SKT-GFM-500) & Module area $\left(A_{P V}\right)$ & $1.425 \times 0.652 \mathrm{~m}^{2}$ \\
& Nominal Voltage $\left(V_{B}\right)$ & $2 \mathrm{~V}$ \\
Inverter & Capacity $\left(C_{b a t}\right)$ & $500 \mathrm{Ah}$ \\
Charge Controller & Charge/Discharge Efficiency $\left(\eta_{b a t}\right)$ & $80 \%$ \\
& Efficiency $\left(\eta_{I N V}\right)$ & $0.95 \%$ \\
Wire & Maximum SOC $(S O C m a x)$ & $100 \%$ \\
Load & Minimum SOC $(S O C m i n)$ & $20 \%$ \\
& Efficiency $\left(\eta_{w}\right)$ & $98 \%$ \\
& AC Voltage $\left(V_{A C}\right)$ & $220 \mathrm{~V}$ \\
& DC Voltage $\left(V_{D C}\right)$ & $12 \mathrm{~V}$ \\
& Daily Average Load Energy $\left(E_{L}\right)$ & $10.12 \mathrm{kWh}$ \\
\hline
\end{tabular}


Table 3. The unit costs for SAPV assets and services.

\begin{tabular}{cc}
\hline Asset/Service & Unit Cost (USD) \\
\hline PV Module & 100/Module (Iraqi Market) \\
PV Maintenance & $0.0542 / \mathrm{Wp} /$ year [12] \\
Battery & 225/Battery [Iraqi Market] \\
Battery Maintenance & $0.003 / \mathrm{Wh} /$ year [12] \\
Replacement Cost & $0.042 \mathrm{Wh} /$ year [12] \\
Charge Controller & $400 /$ Charger [12] \\
Inverter & 800/Inverter [12] \\
Circuit Breaker (CB) & 25/CB [12] \\
Installation & $600[12]$ \\
\hline
\end{tabular}

A PSH of 4.9 (hours) was used for this study, while the number of autonomous days was taken as two days. As for the safety factor, it was set to one in this paper. All components were assumed to last for 25 years, except for the battery bank, which was assumed to be replaced every five years. The inflation and discount rates were taken as $1.5 \%$ and $3.5 \%$, respectively, in this study.

Our aim was to validate the proposed method's result against the result of the numerical method. First, the sizing results of each method are demonstrated. Then, their performance results are presented. After that, the differences between the two methods are explained. The sizing algorithms were developed in MATLAB $^{\circledR}$. The execution platform was an Intel Core i7-3630QM-2.4GH computer with 8 GB of RAM.

The numerical algorithm's sizing results are given in Table 4 . These results were obtained for a desired LLP of 0.01 or less. Using equations $(27-30)$, the obtained PV module range was $(7,95)$ while the battery range calculated was $(10,542,158,125) \mathrm{Wh}$.

Table 4. Numerical method's sizing results.

\begin{tabular}{cc}
\hline Parameter & Value \\
\hline Number of PV panels in series & 1 \\
Number of PV panels in parallel & 63 \\
Total number of PV panels & 63 \\
Number of batteries in series & 6 \\
Number of batteries in parallel & 11 \\
Total number of batteries & 66 \\
LLP & 0.00968 \\
LCC (USD) & $72,993.1218$ \\
\hline
\end{tabular}

According to [39], the recommended values of the mutation factor $(F)$ and crossover rate $(C R)$ are 0.75 and 0.5 , respectively. The $F$ and $C R$ values enable the proposed algorithm to improve its performance in terms of convergence toward the global optimal solution. In the meanwhile, the population size is assumed to be 50 times the number of decision variables to increase the diversity of the obtained non-dominated solutions [39]. The proposed method's results are listed in Table 5. These results are for the system that has an LLP of 0.01 or less. Meanwhile, the complete Pareto front is illustrated in Figure 7. 
Table 5. DEMO-based SAPV sizing method's results.

\begin{tabular}{ccccccccc}
\hline $\begin{array}{c}\text { Run } \\
\text { No. }\end{array}$ & $\begin{array}{c}\text { Parallel } \\
\text { PV }\end{array}$ & $\begin{array}{c}\text { Parallel } \\
\text { Batteries }\end{array}$ & $\begin{array}{c}\text { Series } \\
\text { PV }\end{array}$ & $\begin{array}{c}\text { Series } \\
\text { Battery }\end{array}$ & $\begin{array}{c}\text { Total } \\
\text { Number } \\
\text { of PV }\end{array}$ & $\begin{array}{c}\text { Total } \\
\text { Number of } \\
\text { Batteries }\end{array}$ & LLP & LCC (\$) \\
\hline 1 & 65 & 11 & 1 & 6 & 65 & 66 & 0.0090665 & $73,384.1533$ \\
2 & 63 & 11 & 1 & 6 & 63 & 66 & 0.009680306 & $72,993.12183$ \\
3 & 62 & 11 & 1 & 6 & 62 & 66 & 0.010018332 & $72,797.60607$ \\
4 & 63 & 11 & 1 & 6 & 63 & 66 & 0.009680306 & $72,993.12183$ \\
5 & 63 & 11 & 1 & 6 & 63 & 66 & 0.009680306 & $72,993.12183$ \\
6 & 65 & 11 & 1 & 6 & 65 & 66 & 0.0090665 & $73,384.1533$ \\
7 & 62 & 11 & 1 & 6 & 62 & 66 & 0.010018332 & $72,797.60607$ \\
8 & 62 & 11 & 1 & 6 & 62 & 66 & 0.010018332 & $72,797.60607$ \\
9 & 63 & 11 & 1 & 6 & 63 & 66 & 0.009680306 & $72,993.12183$ \\
10 & 64 & 11 & 1 & 6 & 64 & 66 & 0.009343939 & $73,188.63758$ \\
11 & 63 & 11 & 1 & 6 & 63 & 66 & 0.009680306 & $72,993.12183$ \\
12 & 63 & 11 & 1 & 6 & 63 & 66 & 0.009680306 & $72,993.12183$ \\
\hline
\end{tabular}

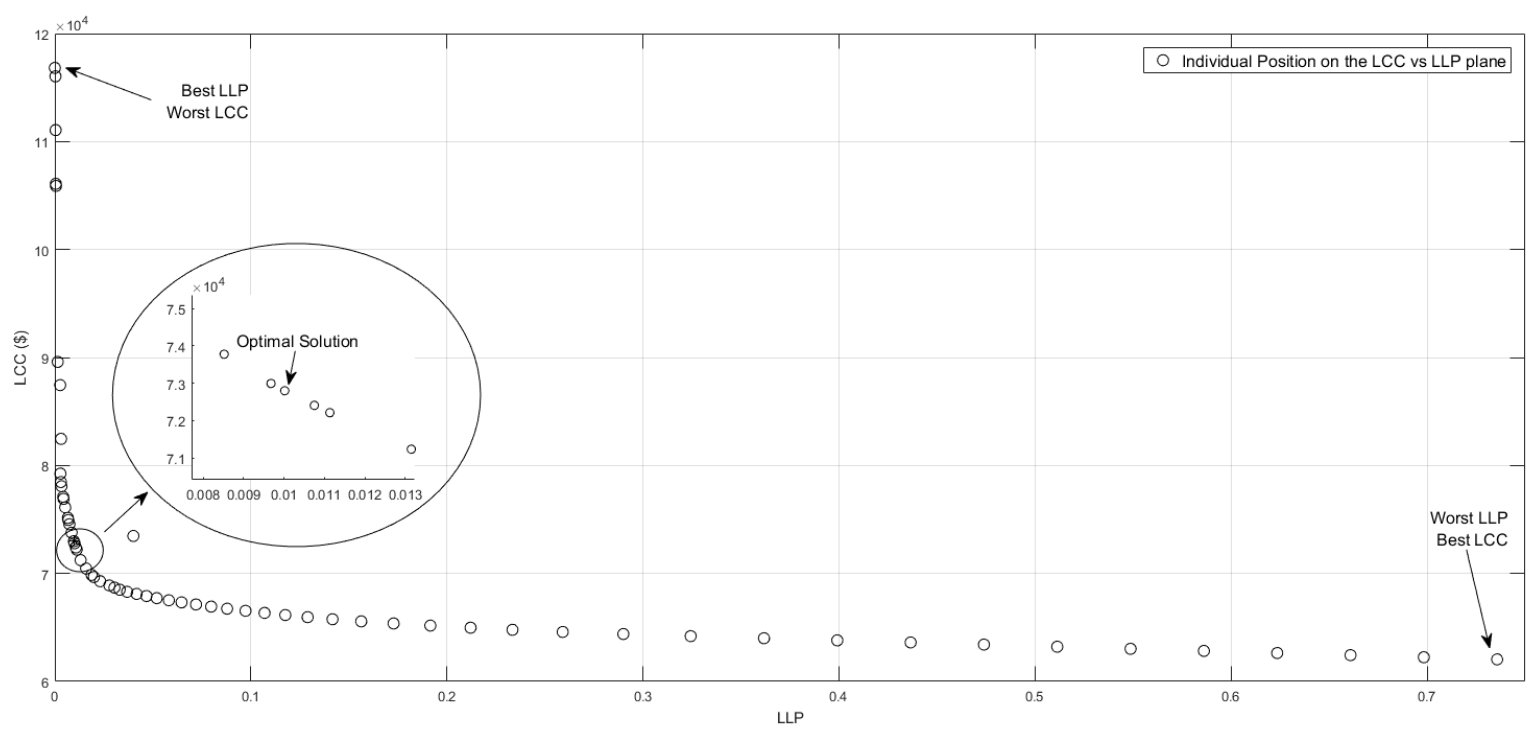

Figure 7. Pareto front of differential evolution multi-objective optimization (DEMO).

Since DEMO is a random searching algorithm, its consistency must be tested. Therefore, the proposed method was run 12 times to see if the same results can be obtained upon every execution. The sizing result for the 12 runs are presented in Table 5 .

In order to the check the performance of the proposed system, a performance simulation is conducted as shown in Figure 8. This figure shows four main issues, which are the power balance between PV array, load, and battery. Meanwhile, the second part shows the deficit energy occurrence. 

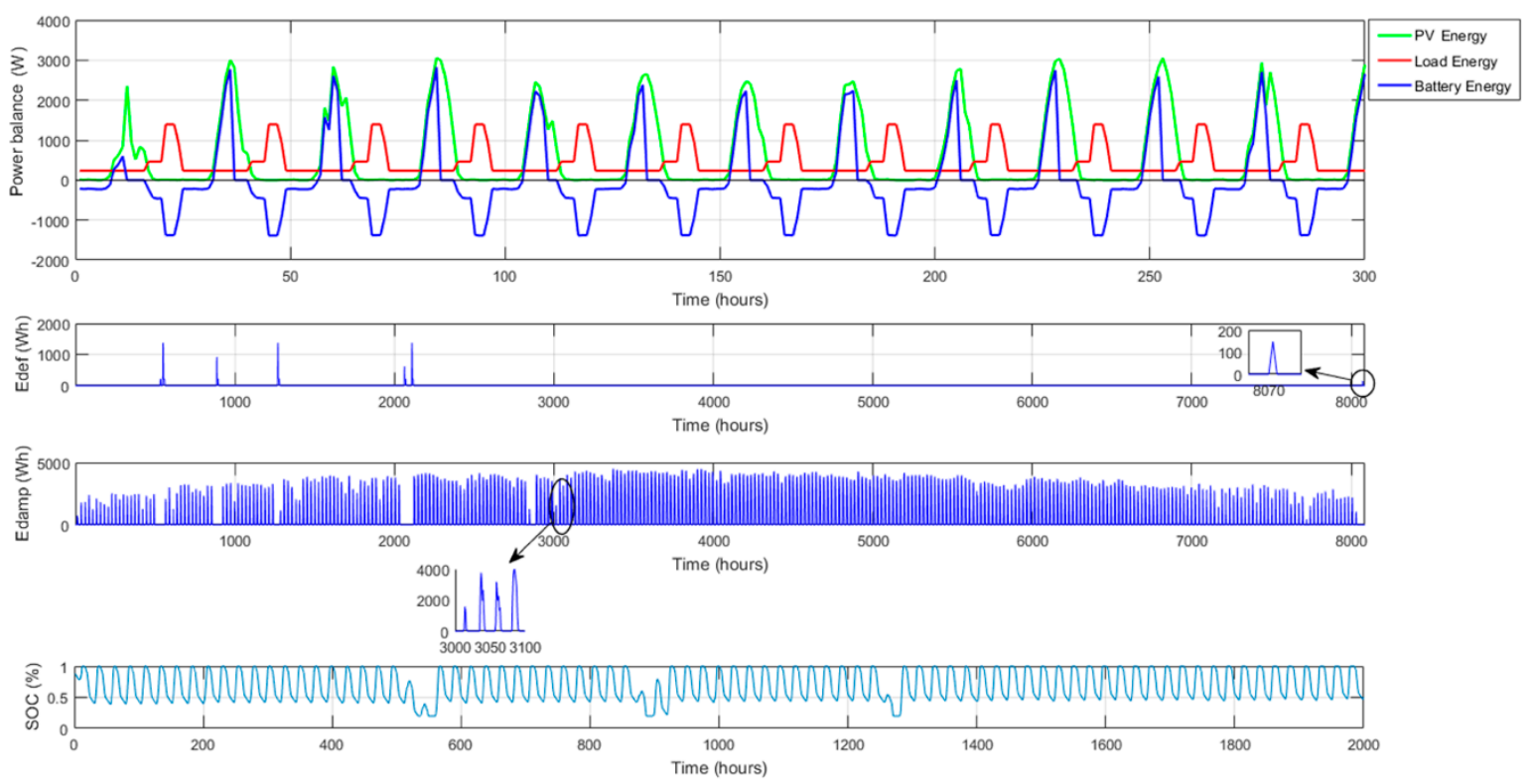

Figure 8. SAPV performance parameters.

The third and the fourth parts show the damped energy as well as the battery state of charge during the simulation, respectively. From the figure, it is very clear that the loss of load probability was really low, whereas about $98 \mathrm{~h}$ of the year were recorded as shortage hours as the PV system could not fulfil the load demand. These shortage incidents were mainly in January and December where the solar energy was really low. As for the damped energy, it is also clear that the system produced unneeded energy during the year. The maximum excess energy that occurred was $4.494 \mathrm{KWh}$.

To show the significance of the proposed method, sizing algorithms are listed in Table 6 and show the difference between the proposed method and the numerical algorithm method. The proposed sizing method took about 0.0369 of the numerical method's time to converge. For the same search space, since DEMO requires only about 0.23 of the simulations required by numerical method, the time impact of simulations would be less on DEMO.

Table 6. Performance parameters of the two sizing algorithms.

\begin{tabular}{ccc}
\hline Sizing Method/Parameter & Execution Time (Hour) & No. of Simulations \\
\hline Numerical algorithm & 107.5 & 25,960 \\
DEMO-based sizing algorithm & 3.967 (Average) & 6800 \\
\hline
\end{tabular}

\section{Conclusions}

Due to the importance of sizing in promoting the use of SAPVs, many attempts have been made to arrive at good sizing methods. Conventional sizing methods suffer from either low accuracy or long computational times. AI is a promising tool that can be used to overcome the defects of classical sizing methods. Several studies have successfully utilized AI techniques in sizing. This work aimed at advancing the field of AI-based SAPV sizing by using a recently developed AI technique. DEMO was used to optimize two conflicting objective functions, the reliability and cost of the SAPV. LLP was used to evaluate the system reliability while the cost of system was estimated using LCC. The resulting method was faster than and as nearly accurate as a numerical method. This study can be extended by adding more PV module and battery commercial models to the optimization problem. This will allow designers to find the optimal SAPV configuration from a set of components brands available in the market. Another possible extension is the application of MCDM to the resulting range of solutions. 
Author Contributions: Conceptualization, T.K. and D.H.M.; methodology, T.K. and D.H.M.; validation, T.K. and D.H.M.; formal analysis, T.K. and D.H.M.; investigation, T.K. and D.H.M.; writing-original draft preparation, T.K. and D.H.M.; writing-review and editing, T.K. and D.H.M. All authors have read and agreed to the published version of the manuscript.

Funding: This research receives no external funding.

Acknowledgments: One of the authors would like to acknowledge Mustansiriyah University (www. uomustansiriyah.edu.iq) Baghdad-Iraq for supporting him to conduct the present work.

Conflicts of Interest: The authors declare no conflict of interest.

\section{References}

1. Ayop, R.; Isa, N.M.; Tan, C.W. Components sizing of photovoltaic stand-alone system based on loss of power supply probability. Renew. Sustain. Energy Rev. 2018, 81, 2731-2743. [CrossRef]

2. Monaaf, D.A.; Al-falahi, S.D.G.; Jayasinghe, H.E. A review on recent size optimization methodologies for standalone solar and wind hybrid renewable energy system. Energy Convers. Manag. 2017, 143, $252-274$. [CrossRef]

3. Kamali, S. Feasibility analysis of standalone photovoltaic electrification system in a residential building in Cyprus. Renew. Sustain. Energy Rev. 2016, 65, 1279-1284. [CrossRef]

4. Sharma, V.K.; Colangelo, A.; Spagna, G. Photovoltaic technology: Basic concepts, sizing of a stand alone photovoltaic system for domestic applications and preliminary economic analysis. Energy Convers. Manag. 1995, 36, 161-174. [CrossRef]

5. Petrakopoulou, F. On the economics of stand-alone renewable hybrid power plants in remote regions. Energy Convers. Manag. 2016, 118, 63-74. [CrossRef]

6. Arvind Chel, G.N.; Tiwari, A.C. Simplified method of sizing and life cycle cost assessment of building integrated photovoltaic system. Energy Build. 2009, 41, 1172-1180. [CrossRef]

7. Al-Salaymeh, A.; Al-Hamamre, Z.; Sharaf, F.; Abdelkader, M.R. Technical and economical assessment of the utilization of photovoltaic systems in residential buildings: The case of Jordan. Energy Convers. Manag. 2010, 51, 1719-1726. [CrossRef]

8. Shukla, A.K.; Sudhakar, K.; Baredar, P. Design, simulation and economic analysis of standalone roof top solar PV system in India. Sol. Energy 2016, 136, 437-449. [CrossRef]

9. Dufo-López, R.; Lujano-Rojas, J.M.; Bernal-Agustín, J.L. Comparison of different lead-acid battery lifetime prediction models for use in simulation of stand-alone photovoltaic systems. Appl. Energy 2014, 115, 242-253. [CrossRef]

10. Lee, M.; Soto, D.; Modi, V. Cost versus reliability sizing strategy for isolated photovoltaic micro-grids in the developing world. Renew. Energy 2014, 69, 16-24. [CrossRef]

11. Bouabdallah, A.; Olivier, J.C.; Bourguet, S.; Machmoum, M.; Schaeffer, E. Schaeffer, Safe sizing methodology applied to a standalone photovoltaic system. Renew. Energy 2015, 80, 266-274. [CrossRef]

12. Ibrahim, I.A.; Khatib, T.; Mohamed, A. Optimal sizing of a standalone photovoltaic system for remote housing electrification using numerical algorithm and improved system models. Energy 2017, 126, 392-403. [CrossRef]

13. Koca, A.; Oztop, H.F.; Varol, Y.; Koca, G.O. Estimation of solar radiation using artificial neural networks with different input parameters for Mediterranean region of Anatolia in Turkey. Expert Syst. Appl. 2011, 38, 8756-8762. [CrossRef]

14. Egido, M.; Lorenzo, E. The sizing of stand alone PV-system: A review and a proposed new method. Sol. Energy Mater. Sol. Cells 1992, 26, 51-69. [CrossRef]

15. Fragaki, A.; Markvart, T. Stand-alone PV system design: Results using a new sizing approach. Renew. Energy 2007, 33, 162-167. [CrossRef]

16. Jakhrani, A.Q.; Othman, A.; Rigit, A.R.H.; Samo, S.R.; Kamboh, S.A. A novel analytical model for optimal sizing of standalone photovoltaic systems. Energy 2012, 46, 675-682. [CrossRef]

17. Okoye, C.O.; Solyalı, O. Optimal sizing of stand-alone photovoltaic systems in residential buildings. Energy 2017, 126, 573-584. [CrossRef]

18. Khatib, T.; Elmenreich, W. An Improved Method for Sizing Standalone Photovoltaic Systems Using Generalized Regression Neural Network. Int. J. Photoenergy 2014, 2014, 748142. [CrossRef] 
19. Maleki, A.; Pourfayaz, F.; Hafeznia, H.; Rosen, M.A. A novel framework for optimal photovoltaic size and location in remote areas using a hybrid method: A case study of eastern Iran. Energy Convers. Manag. 2017, 153, 129-143. [CrossRef]

20. Mohamed, A.F.; Elarini, M.M.; Othman, A.M. A new technique based on Artificial Bee Colony Algorithm for optimal sizing of stand-alone photovoltaic system. J. Adv. Res. 2014, 5, 397-408. [CrossRef]

21. Aziz, N.I.A.; Sulaiman, S.I.; Shaari, S.; Musirin, I.; Sopian, K. Optimal sizing of stand-alone photovoltaic system by minimizing the loss of power supply probability. Sol. Energy 2017, 150, 220-228. [CrossRef]

22. Heydari, A.; Askarzadeh, A. Optimization of a biomass-based photovoltaic power plant for an off-grid application subject to loss of power supply probability concept. Appl. Energy 2015, 165, 601-611. [CrossRef]

23. Askarzadeh, A. A discrete chaotic harmony search-based simulated annealing algorithm for optimum design of PV/wind hybrid system. Sol. Energy 2013, 97, 93-101. [CrossRef]

24. Movahediyan, Z.; Askarzadeh, A. Multi-objective optimization framework of a photovoltaic-diesel generator hybrid energy system considering operating reserve. Sustain. Cities Soc. 2018, 41, 1-12. [CrossRef]

25. Mellit, A. ANN-based GA for generating the sizing curve of stand-alone photovoltaic systems. Adv. Eng. Softw. 2010, 41, 687-693. [CrossRef]

26. Benmouiza, K.; Tadj, M.; Cheknane, A. Classification of hourly solar radiation using fuzzy c-means algorithm for optimal stand-alone PV system sizing. Int. J. Electr. Power Energy Syst. 2016, 82, 233-241. [CrossRef]

27. Khatib, T.; Ibrahim, I.A.; Mohamed, A. A review on sizing methodologies of photovoltaic array and storage battery in a standalone photovoltaic system. Energy Convers. Manag. 2016, 120, 430-448. [CrossRef]

28. Zheng, Y.; Chen, S.; Lin, Y.; Wang, W. Bio-Inspired Optimization of Sustainable Energy Systems: A Review. Math. Probl. Eng. 2013, 2013, 354523. [CrossRef]

29. Youssef, A.; El-Telbany, M.; Zekry, A. The role of artificial intelligence in photo-voltaic systems design and control: A review. Renew. Sustain. Energy Rev. 2017, 78, 72-79. [CrossRef]

30. Jordehi, A.R. Parameter estimation of solar photovoltaic (PV) cells: A review. Renew. Sustain. Energy Rev. 2016, 61, 354-371. [CrossRef]

31. Muhsen, D.H.; Ghazali, A.B.; Khatib, T.; Abed, I.A. A comparative study of evolutionary algorithms and adapting control parameters for estimating the parameters of a single-diode photovoltaic module's model. Renew. Energy 2016, 96, 377-389. [CrossRef]

32. Muhsen, D.H.; Ghazali, A.B.; Khatib, T.; Abed, I.A. Extraction of photovoltaic module model's parameters using an improved hybrid differential evolution/electromagnetism-like algorithm. Sol. Energy 2015, 119, 286-297. [CrossRef]

33. Kaelo, P.; Ali, M.M. Differential evolution algorithms using hybrid mutation. Comput. Optim. Appl. 2007, 37, 231. [CrossRef]

34. Castañer, L.; Silvestre, S. Modelling Photovoltaic Systems Using PSpice ${ }^{\circledR}$; Wiley: Hoboken, NJ, USA, 2002; pp. 1-358. [CrossRef]

35. Muhsen, D.H.; Khatib, T.; Abdulabbas, T.E. Sizing of a standalone photovoltaic water pumping system using hybrid multi-criteria decision making methods. Sol. Energy 2018, 159, 1003-1015. [CrossRef]

36. Ishaque, K.; Salam, Z.; Mekhilef, S.; Shamsudin, A. Parameter extraction of solar photovoltaic modules using penalty-based differential evolution. Appl. Energy 2012, 99, 297-308. [CrossRef]

37. Jiang, L.L.; Maskell, D.L.; Patra, J.C. Parameter estimation of solar cells and modules using an improved adaptive differential evolution algorithm. Appl. Energy 2013, 112, 185-193. [CrossRef]

38. Khatib, T.; Sopian, K.; Kazem, H.A. Actual performance and characteristic of a grid connected photovoltaic power system in the tropics: A short term evaluation. Energy Convers. Manag. 2013, 71, 115-119. [CrossRef]

39. Muhsen, D.H.; Ghazali, A.B.; Khatib, T. Multiobjective differential evolution algorithm-based sizing of a standalone photovoltaic water pumping system. Energy Convers. Manag. 2016, 118, 32-43. [CrossRef]

(C) 2020 by the authors. Licensee MDPI, Basel, Switzerland. This article is an open access article distributed under the terms and conditions of the Creative Commons Attribution (CC BY) license (http://creativecommons.org/licenses/by/4.0/). 